\title{
The Effects Of Using Interactive Teaching Programs On Preschool Children's Literacy Development: Case Study
}

Nahla M. Gahwaji, King Abdulaziz University, Saudi Arabia

\begin{abstract}
This paper presents findings of a case study that investigates the effects of using interactive teaching programs on literacy development for preschool children. The significant of this study comes from the lack of studies associated with using interactive teaching programs for preschool children in Saudi Arabia. Data are presented from analyzing children's test scores, teachers' and parents' questionnaires, and classroom observations. The subjects of the study consisted of (38) children in three Kg-3 classrooms in a private preschool center at Jeddah, Saudi Arabia. The results indicated that using interactive teaching programs have effects on increasing word acquisition, oral language, and written words which are components of emergent literacy. According to the study results, the researcher suggests several teaching strategies which may be of assistance to teachers in relation to literacy development for preschool children. Finally, the study recommends undertaking more studies related to using interactive teaching programs for preschool provision in Saudi Arabia.
\end{abstract}

Keywords: Interactive teaching programs; Literacy development; Preschool children

\section{INTRODUCTION}

¿ nteractive learning describes a method of acquiring information through hands on. The opposite of interactive learning is passive learning, which is merely observing a learning process or just listening to information. Preschool children begin learning both interactively and passively. They acquire much of their language through passive learning, while much of their physical development is a result of interactive learning. As children grow, they continue to learn both passively and interactively and to respond differently to each method. Literacy development begins in the very early stages of childhood, even though the activities of young children may not seem related to reading and writing. Early behaviors such as "reading" from pictures and "writing" with scribbles are examples of emergent literacy and are an important part of children's literacy development. With the support of parents, caregivers, early childhood educators, and teachers, as well as exposure to a literacy-rich environment, children successfully progress from emergent to conventional reading. The theoretical and research-based knowledge of child development in general and of literacy development in particular provides an understanding of the literacy acquisition of young children and suggests strategies that can help children become successful, confident readers and writers.

Learner's interactivity which are the active involvement, participation, and engagement of the individual in the learning process. Whitehead (1999) states "Learning activities are coordinated actions that exercise basic intellectual skills, thought processes, and analysis techniques". Good interactive teaching programs begin with the presentation of content, and then continue with activities that encourage an individual to reflect on, discuss, and apply the content. Most Interactive teaching programs interact with children on a progressive level, meaning that the software program enables the computer to advance the material as the child grasps each concept successfully or to review a concept he or she is having difficulty with (Haugland, \& Wright 1997). 
Other examples of interactive learning include units, which are present in many preschool classrooms. Units are simply series of activities that put emphasis on specific learning concept. Children move from one unit to other, where learning is reinforced through each activity (Lewin, 2000). Information and Computer Technology (ICT) literacy is the interest, attitude and ability of individuals to appropriately use digital technology and communication tools to access, manage, integrate and evaluate information, construct new knowledge, and communicate with others in order to participate effectively in society (Van Joolingen, 2004).

\section{RESEARCH QUESTION AND OBJECTIVES}

The main question of this study is "What are the effects of interactive teaching programs on preschool children's literacy development?"

The research objectives are as follows:

- $\quad$ To analyze evidence regarding the ways in which teachers can make use of interactive teaching programs in supporting literacy development for preschool children.

- $\quad$ To establish whether interactive teaching programs are effective in promoting preschool children's literacy development.

\section{THEORETICAL BACKGROUND}

Reading skills provide a crucial piece of the foundation for children's academic success. Children, who read early well, experience more print exposure and consequent growth in numerous knowledge domains (Echols, West, Stanovich, \& Zahr, 1996; Cunningham \& Stanovich, 1997; Pellin, \& Edmonds, 2001). In contrast, children who lag behind in their reading skills receive less practice in reading than other children do (Pellin, \& Edmonds, 2001), miss opportunities to develop reading comprehension strategies (Al-Biblawi, 2001), often encounter reading material that is too advanced for their skills (Pellin, \& Edmonds, 2001). Although the development of literacy occurs without significant problems for the majority of children, the Preschool Curriculum Evaluation Research (PCER) in Florida, USA estimated that one in three children experience significant difficulties in learning to read (Wood, 2002).

There is a strong continuity between the literacy skills with which children enter school and their later academic performance. Previous research has identified a number of potentially important components of emergent literacy. West, Denton, and Reaney (2001) recently outlined different components of emergent literacy skills and identified three factors that appear to associated with preschool children's later word- decoding abilities: oral language, phonological processing, and print knowledge. In the earliest stages, reading in an alphabetical system involves decoding letters into corresponding sounds and linking those sounds to single words. A substantial body of research has demonstrated positive correlations and longitudinal continuity between individual differences in oral language skills and later differences in reading (Davis \& Shade, 1999). Studies of Saudi preschool children (AlBiblawi, 2001) have demonstrated significant concurrent and longitudinal correlations between children's vocabulary skills and their phonological sensitivity.

Phonological sensitivity refers to sensitivity to and ability to manipulate the sound structure of oral language. A research study in UK has converged on the finding that phonological sensitivity plays a critical and causal role in the normal acquisition of reading (Mioduser, Tur-Kaspa, \& Leitner, 2000). Children who are better at detecting and manipulating syllables, rhymes, or phonemes are quicker to learn to read. In addition to oral language and phonological sensitivity, aspects of children's print knowledge seen to be important emergent literacy skills (Haugen, 1998). For example, knowledge of the alphabet (i.e., knowing the names of letters and the sounds they represent) at entry into school is one of the strongest single predictors of short- and long term success in learning to read (Lewin, 2000).

Most of the literature points to the use of ICT in preschool settings as being what Cuban (2001) referred to as a 'being addition'. In other words, computers have been brought into preschool centers as a supplement to existing practices, and teachers perpetuate existing ways of working while accommodating the new technologies. 
Liang and Johnson (1999) described ICT as a 'wonderful tool' for formative assessment, offering ways to store art crafts, pictures and narratives. Most Interactive teaching programs interact with children on a progressive level, meaning that the software program enables the computer to advance the material as the child grasps each concept successfully or to review a concept he or she is having difficulty with (Haugland \& Wright, 1997).

Computer technology offered great amount of possibilities in the early childhood settings as well and the potential value of a personal computer in early child development has been debated consistently among both practitioners and researchers for many years. Building upon the work of educational researchers and practitioners, the National Association for the Education of Young Children (NAEYC) has acknowledged that computers can enhance young children's learning and collaborative experiences with peers and has issued guidelines for selecting software and using computers in the classroom (NAEYC, 1996; Kumtepe, (2006). Computers are viewed as having tremendous potential to benefit young children when they are used in a developmentally appropriate way (Haugland \& Wright, 1997; Haugland, 2000). Used in appropriate ways, the computer is an invaluable resource that fits children's learning style. It also has a unique potential to provide scaffolding opportunities enabling children to successfully explore and master tasks that would be impossible without a computer (Char, 1990). Furthermore, it also provides teachers a unique opportunity to access information and reach other people to share the knowledge.

Research supports the selection of interactive teaching programs that allows children to decide pace and direction, and contains sound, voice, and music (Talley, Lancy, \& Lee, 1997). Other beneficial programs characteristics include: open-ended learning tasks with animated routines and directions that can be paused and resumed, or halted, and swift feedback to children in order to nurture their interest.

\section{METHODOLOGY}

The case study approach (Hitchcock \& Hughes, 1995) was used to analyze the effects of using interactive teaching programs on literacy development for preschool children. The subjects of the study consisted of (38) children in three $\mathrm{Kg}-3$ classes in a private preschool center at Jeddah, Saudi Arabia. Also, the sample consisted of 6 class teachers, 1 head teacher, and 37 parents. The case study approach was very suitable for this study, since the research was conducted after an agreement from the preschool center to set up whiteboards in the three classrooms, and include interactive teaching programs as part of its curriculum. All the teachers were provided with a complete guide for the interactive teaching programs. The guide provides teachers different ways of teaching key literacy concepts (vocabulary, print awareness, narrative skills, letter knowledge, and phonological awareness), gives detailed overview of each of the interactive teaching programs, and includes screenshots and instructions on how to use them.

The study integrated different methods which are observations, questionnaires, and children's tests. Two observation schedules were developed for this study that were adapted from the Effective Early Learning (EEL) Project (Pascal et al., 1997). The Child Tracking Schedule is used to gain a snapshot of the child's day and provide information on literacy learning experiences, the amount of interactive teaching programs offered to the child (known as the zone of initiative), how children are organized in terms of grouping, interactions between children and teachers in the computer's corner, and the involvement of the children in additional literacy activities. The Involvement Schedule is used to gauge the quality of the educational experience in which the child is engaged, and the level of learning experienced by the child, in which a high score for the level of involvement indicates deep level learning (Mcinnes, 2002). There were three sets of children literacy skills. The teachers administered the tasks individually and during observations the amount of support each child needed to perform the test successfully was recorded:

$1=$ no prompts (e.g., "push the Enter key")

$2=$ general encouragement (e.g., "this is something you have done before")

$3=$ an explicit hint (e.g., " look for the letter in the middle")

$4=$ exact instructions (e.g., "choose this word)

The literacy skills were selected from the skills set in the interactive teaching programs that were chosen for this study, and were arranged in sets of increasing difficulty: 5 (vocabulary), 5 (print awareness), 5 (narrative 
skills), 4 (letter knowledge), and 5 (phonological awareness) skills. Items were averaged to produce 1-4 scores for each of the five skills sets. Scores were inverted so that a high score was positive. Non formal observations were conducted at the classrooms, several multiple opportunities for observation identified relevant features of its educational environments. The teachers used a 3-point scale containing words (Child really enjoys it, It is fine, Child does not enjoy it) and graphics (Happy, neutral, sad faces) to measure the child enjoyment of the interactive teaching programs. Also, self- directed child exploration consisted of 8 items for which teachers indicated the number of minutes per week the typical child would be engaged in self- directed examination of each computer use (e.g., reading an e-book).

Questionnaires are provided to parents, and teachers. Information concerning children's family and home literacy experiences was obtained through parents' questionnaires. Thirty seven parents completed questionnaires which represented their attitudes to instructional use of interactive teaching programs consisted of 15 Likert items (e.g., I think children are more excited when they use computers) (adapted from Stephen, Brown, Cope \& Waterhouse, 2001). Parent's computer use was a single item measuring how frequent the parent used a computer (daily, weekly, monthly, not at all); scores on the items were used to distinguish users from non users. Parents also provided demographic information: age (20-24, 25-29, 30+), education (higher education, college level, high school, non-formal schooling), and home computer ownership (yes/no).

Teachers' questionnaires include one set of teacher outcome measure which consists of three measures of teachers' practice. The first one is teachers' personal computer use which consisted of eleven items in which teachers indicated on a 7 - point scale $(1,1-2,3-5,6-10,11-15,16-20,20+)$ how many times per month they used a computer for various functions (e.g., word processing, writing children's reports, sending e-mails). The items were averaged to create a 1-7 score. The second component is children's computer use; teachers indicated how often children engaged in computer activities, using a 3-point scale for (weekly, less than weekly, and never). The items were averaged to produce a 1-3 score. The third component is the direct teaching of computer skills where teachers indicated how many minutes per week they would spend on direct instructions of computer use. Teachers responses to a 4-point scale $(1,1-15,16-30,30+)$ were averaged to produce a 1-4 score on each measure. Teachers also provided demographic information: teachers' education (BA or equivalent, high school diploma or equivalent), and years of teaching $(1-5,6-10,11-15,16+)$.

The children were tested two times (Time 1, and Time 2) during the study. Children's progress was assessed controlling for prior attainment at entry to the study at age 5+. Time 1 test took place 4 weeks prior to the ending of the first term of the preschool year so that the children had at least three months exposure to literacy activities without any interactive teaching programs. Testing took place over two sessions, each lasting 20-25 minutes, with a fixed order of presentations of tests, and was conducted individually in a quiet room by the class teachers. Time 2 test, which was similarly conducted, took place exactly three months later, after the introduction of interactive teaching programs. Children's test included 5 outcomes of literacy skills: vocabulary, print awareness, narrative skills, letter knowledge, and phonological awareness.

\section{PHONOLOGICAL SENSITIVITY MEASURES}

Each of the two phonological sensitivity tasks was preceded by practice trials which are included in the interactive teaching program to teach children the task (e.g., blending or deleting word sounds). For all tasks, corrective feedback was given during the practice trials, but no feedback was given during the test trials. Many items on the phonological sensitivity tasks used pictures to reduce memory demands on the children. All tasks that were administered at Time 1 and Time 2 included the same items. In both tasks, children were presented with three pictured words (e.g., rain, sail, nail; car, cat, egg), which were displayed during the test, and were asked to select the one that did not rhyme with (or that sounded different from) or did not sound the same at the beginning of the word as (or that sounded different at the beginning of the word from) the other two words. Two practice trials and 11 test trials were presented to all children. A blending task required children to combine word elements to form a word. Three practice items and the first eight test trials were presented both out loud and with pictures; the remaining test trials were presented verbally only. In both picture and non picture trials, the first five items required blending single-syllable words to form compound words, and the remaining items required blending syllables or phonemes. For picture items involving compound words, the children were shown two pictures, names of them were vocally 
heard, and then a question appears on the screen and vocally heard asking the child what word would be produced if he or she said them together (e.g., "What do you get when you say black . . board together?"). All practice items required the blending of compound words, and during the practice the test emphasized the nature of the task by putting the pictures together.

For the Time 1 test of the sample, there were 20 test trials, consisting of 10 word-blending items, 5 syllable blending items, and 5 phoneme-blending items. At the Time 2 test, there were 40 test trials, consisting of all of the Time 1 items followed by 4 additional syllable-blending items and 16 additional phoneme-blending items. These additional syllable and phoneme items were included in the Time 2 test to reduce the chances of children's scoring at ceiling levels. During both tests, testing was discontinued after a child missed 5 consecutive trials.

An elision task required children to say a word minus a specific sound. Two practice items and the first eight test trials were presented both verbally and with pictures; the remaining test trials were presented verbally only. In both picture and non picture trials, the first four items required deleting a single-syllable word from a compound word to form a new word. Subsequent items in both picture and non picture trials required deletion of a syllable or a phoneme from a word to form a new word. For picture items involving compound words, two pictures were displayed with names (e.g., "This is a cow, and this is a boy"), asked the child to say the compound (i.e., "cowboy"), and then asked the child to delete part of it.

During both practice trials, which used compound words, the test emphasized the nature of the task by removing the picture of the word to be deleted. At the Time 2 test, there were 34 test trials, consisting of all of the Time 1 items followed by an additional 17 phoneme-level items. These additional phoneme items were included to reduce the chances of children's scoring at ceiling levels. During both tests, testing was discontinued after a child missed 5 consecutive trials.

\section{LETTER KNOWLEDGE MEASURES}

For both Time 1 and Time 2 tests of the sample, two tasks assessed different aspects of letter knowledge. Letter-name knowledge task required children to name all 26 uppercase letters that were presented individually in random order on the screen. A letter-sound knowledge task required children to name the sound made by each letter when it appeared in a word. All 26 uppercase letters were presented individually in random order on the screen. If children responded with the letter name or a word that started with the letter (e.g., "cat" for C), they were prompted to provide the letter sound; however, credit for a correct response was given if children provided the long vowel sound for vowels.

\section{PRINT CONCEPTS MEASURE}

The children at Time 1 completed an environmental print task. On this task, children were shown 10 pictures of print in environmental context (e.g., a stop sign, a Pepsi machine, and Saudi milk can) and were asked what each said. Children were also shown the same print as printed text out of context and were asked what it said. At both Time 1 and Time 2 for the sample, a print test was used to assess the children's print knowledge using an ebook demonstrating a story. Items in this test require children to express understanding of the Left-to-right and topto-bottom direction of print in a book, the sequence and direction in which print progresses from front to back across pages, the difference between the covers and the pages of a book, the difference between pictures and print on a page, and the meaning of elements of punctuation, including spaces between words and periods at the ends of sentences.

\section{WORD DECODING MEASURES}

At Time 2 test, children completed word identification test which include a task requiring them to decode 28 frequent words printed individually on the screen (e.g., ship, train, and car). 


\section{ANALYSIS}

A series of multivariate analyses of variance on data using the general linear model program in SPSS (a regression approach to analysis of variance) were conducted. For each of child outcomes (literacy skills, computer use, and cognition) multivariate and univariate effects were examined. In these analyses there were three betweensubject variables: time (Time 1 and Time 2 tests, e.g., before and after interactive teaching programs), gender (male or female), and parental use of computers. There was a focus on the main effects of time and two- way interactions of time with other variables. Also gender, parent and home learning environment factors were included in the models to establish the extent to which interactive teaching programs influenced children's literacy development. Consistency in effects studied for 5 outcomes of literacy skills: vocabulary, print awareness, narrative skills, letter knowledge, and phonological awareness.

\section{RESULTS}

As for the observation results, there was significant variability between learning corners (Blocks, Manipulative, Art.....) in terms of materials available to the children and the activity structure. Generally, the curriculum was designed to foster social and interpersonal skill growth and to introduce the children to a variety of educationally relevant concepts such as letters, numbers, colors, etc,. There was never any observation of any explicit attempts to teach the children to read. The teachers had at least offered some letter knowledge instructions to children, but most of this was informal. A number of parents commented that they encouraged explicit teaching. The three classes had a daily activity schedule, including free play, story time, and small group art and craft projects.

Before Time 1 test, results of the Involvement Schedule signified that the center incorporated some teacher-directed classroom activities (typically art and craft); however, the majority of children's time was spent in self-directed activities in and out of the classroom. Also the results indicated that a child have a chance to spend 20 minutes daily in the computer's corner but this is not the case for all children since the class rules allow only two children at a time to share the corner. After Time 1 test, it was noted that although the time available for practicing interactive teaching programs at the computer's corner (self- directed activity) is limited, the interaction between children and teachers is constructive in the circle time (teacher- directed activity).

Information concerning children's family and home literacy experiences obtained through the parents' questionnaires. Since the study is situated in Saudi Arabia, Arabic is the children's first language while English was the primary language taught at the preschool center. Although, fewer than 7 parents stated that English was not spoken at home, most children communicate in English during the school day. The parents had completed on average 16 years of education (over $70 \%$ of parents were college graduates). Parents stated that they have a significant number of children's books at home $(\mathrm{M}=89.47, \mathrm{SD}=67.5)$. Children were reported to be read to frequently at home $(\mathrm{M}=6.69$ times per week, $\mathrm{SD}=3.22)$; and shared reading (reading with the child) had started early for children $(\mathrm{M}=6.37$ months, $\mathrm{SD}=6.18)$.

Teachers' questionnaires include one set of teacher outcome measure which consisted of three measures of teacher's practice. All teachers stated that they use computers daily in various ways $(M=)$, and especially with the set up of Whiteboards in the classrooms, they were required to use them in their daily practice. Self- directed child exploration consisted of 8 items for which teachers indicated the number of minutes per week the typical child would be engaged in self- directed examination of each computer use (e.g., reading an e-book). For direct teaching of computer skills teachers indicated how many minutes per week they would spend on direct instructions of same 8 categories of computer use. Teachers responses to a 4-point scale $(1,1-15,16-30,30+)$ were averaged to produce a 1-4 score on each measure. As for teachers' education, only one teacher has a Bachelor degree in Sociology with an educational diploma, while the remaining six have a Bachelor degree in Early childhood, and for years of teaching, all teachers reported that they have less than 5 years of experience.

As for children's test scores, Table (1) displays the reliabilities, means and standards for children outcome variables in the study. Most alphas were in $.70 \mathrm{~s}$ and $.80 \mathrm{~s}$, with two in $.60 \mathrm{~s}$. Parental attitudes to computers (alpha $=.84)$ and other independent variables are not shown. A series of multivariate analyses of variance using 
GLM were conducted. In the first round, the dependent variables were five sets of literacy skills. The between subject variables were time (Time 1 and Time 2 tests), gender, and parental use of computer. The interactions of time with gender and time with parental use of computer were also examined; all other interactions were suppressed. The top panel of Table (1) shows there were significant multivariate effects. Children literacy skills were higher after the introduction of interactive teaching programs than they were prior to Time 2 tests. The interactive teaching programs accounted for $25 \%$ of the variance in literacy skills, a large effect. As well, children scored higher in Time 2 than in Time 1 tests, accounting for an additional 10\% of the variance. None of the other multivariate effects (gender and the two-way interactions with time) were statistically significant. Also, results indicated that the children's enjoyment level has increased from Time 1 to Time 2.

Table 1 Children's outcomes: Means and Standard Deviation

\begin{tabular}{|llllll|}
\hline & Alpha & Time 1 & \multicolumn{3}{c|}{ Time 2 } \\
\cline { 3 - 6 } & & Means & SD & Means & SD \\
\hline Children literacy skills & & & & & \\
Vocabulary & .75 & 3.60 & .50 & 3.82 & .35 \\
Print awareness & .75 & 2.97 & .78 & 3.50 & .62 \\
Narrative skills & .75 & 2.40 & .76 & 2.70 & .53 \\
Letter knowledge & .73 & 2.53 & .93 & 3.26 & .71 \\
Phonological awareness & .62 & 2.34 & 1.07 & 3.23 & .91 \\
& & & & & \\
Computer use & .75 & 2.11 & .45 & 2.47 & .34 \\
Children cognition about computers & & & & & \\
Enjoyment & .69 & 2.59 & .34 & 2.64 & .30 \\
Self-efficacy & .80 & 2.20 & .50 & 2.49 & .40 \\
\hline
\end{tabular}

Table 2 children's outcomes: Multivariate and Univariate effects

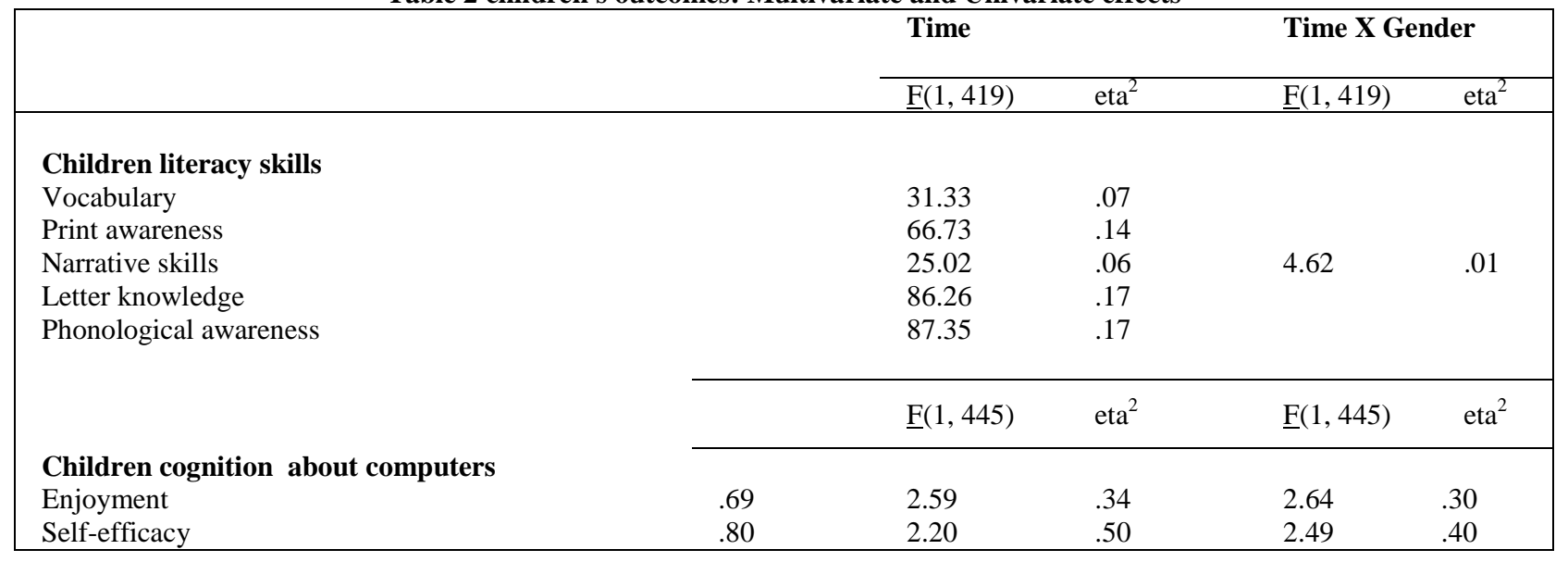

Table (2) shows the significant univariate effects of time and two-way interactions with time. The table shows that interactive teaching programs made a statistically significant contribution to each of the five sets of literacy skills. The strongest impact was on (letter knowledge) and (phonological awareness) two key components of the interactive teaching programs; the weakest were for (vocabulary) in the middle. These are small to medium effects. There was also a small main effect of gender $[\underline{F}(1,419)=25.02, \underline{p}=.4 .62 \text {, eta squared }=.01]_{-}$effect for (narrative skills) only: females scored higher than males.

The second set of children outcomes concerned children cognition about ICT. The dependent variables were enjoyment of ICT and ICT self efficacy (confidence in completing ICT-based tasks). The between-subject variables were time, gender, and children use of computer at home and two-way interactions with time. Table (2) 
shows there were multivariate effects. Children cognition about Interactive teaching programs became more positive after the introduction of interactive teaching programs (11\% of the variance). Analyses of variance (ANOVAs) of Time 2 revealed that sample scored substantially higher than Time 1 on the phonological sensitivity measures (all ps <.001). For all tasks that were the same between Time 1 and Time 2 tests (i.e., all phonological sensitivity tasks and the letter knowledge and word level phonological sensitivity tasks for the sample), within subject ANOVAs revealed that there was significant growth from Time 1 to Time 2 (all ps $<.001$ ).

Table (3) shows the mean involvement scores from the Child Tracking Schedule and the Involvement Schedule. The results indicated that the level of involvement increased from Time 1 to Time 2 for the sample. Therefore according to the rationale underpinning involvement and deep level learning, the higher level of involvement and, therefore, deeper level of learning occurs which means positive impacts on all literacy skills.

Table (4) displays the reliabilities, means, and standard deviations for teacher data. The reliabilities were adequate (.76 -.94). A series of multivariate analyses of variance were conducted in which the dependent variables were teachers' use of computers, teacher efficacy beliefs, and attitudes to computers. There were three betweensubjects variables: time (Time 1, Time 2) teaching experience, and computer personal use. The study did not represent the effects of teacher outcomes since there were too few teachers in the sample.

Table 3 Child Involvement

\begin{tabular}{|lcc|}
\hline & Time 1 & Time 2 \\
\hline Mean involvement from Child Tracking schedule (out of 5) & 3.0 & 3.8 \\
Mean involvement from Involvement Schedule (out of 5) & 3.2 & 4.0 \\
Overall mean involvement (out of 5) & 3.1 & 3.9 \\
\hline
\end{tabular}

Table 4 Teachers' outcomes

\begin{tabular}{|lccccc|}
\hline & Alpha & \multicolumn{2}{c}{ Time 1 } & \multicolumn{2}{c|}{ Time 2 } \\
\cline { 3 - 6 } & & Means & SD & Means & SD \\
\hline Teacher use of computers & & & & & \\
Personal computer use & .80 & 2.24 & .92 & 2.73 & .90 \\
Practice: exploration activities & .91 & 2.21 & .77 & 2.59 & .72 \\
Practice: direct teaching & .94 & 1.96 & .73 & 2.00 & .59 \\
\hline
\end{tabular}

\section{CONCLUSIONS}

Results show positive impact of interactive teaching programs on all literacy skills compared with no experience of interactive teaching programs for other skills (ex. social and Math). There are some individual differences between children in their literacy development; some are outliers due to parent and home influences. The interactive teaching programs count for literacy development of the children where results indicated that a combination of passive and interactive learning is the best way to enforce the concepts that children need to learn throughout their preschool years.

Evidence confirmed that interactive teaching programs are expensive to be used in preschool centers. The cost of the hardware (computer and whiteboard) and the software (the interactive teaching program) is almost 30,000 Saudi Riyals (SR) while the software's license for one year is 6,000 SR per classroom in this study (approximately 9,000 US dollars). Such a major cost is not easy to rationalize if the sole advantages are the small impacts on literacy skills reported in meta-analyses of interactive teaching programs. The data in this study indicated that making interactive teaching programs a central component of preschool curriculum has important collateral advantages beyond its core functions. It adds to children's acquisition of ICT skills essential to subsequent ICT learning, it has a positive impact on children willingness to use interactive programs to learn, and it contributed to increased teacher confidence in using interactive teaching programs as one of their key teaching strategies. This study displays that the adoption of interactive teaching programs in preschool provision, provides a solid cognitive and effective foundation for student access to ICT. The latter is considered as especially important because computer phobia has its roots in the early experiences of children with computers (Fisher, 2000). 
In this study it has been possible to offer only one example of using interactive teaching programs to introduce literacy components to preschool children. Significantly, this study suggests the process of using interactive teaching programs to transform teachers' thinking and actions. While preschool children learn in meaningful ways, their teachers learn as well- in ways that will have lasting impact on integrating ICT resources into other areas of curriculum other than literacy. Preschool centers ought to incorporate interactive teaching through attaining interactive programs and licenses for educational websites to incorporate interactive learning. Teachers should incorporate using whiteboards in their daily lessons to develop their practice and facilitate interactive learning in preschool provision. Modifications to curriculum are necessary, in order to meet the technological changes in preschool centers. Emerging from this research are issues for future considerations. Such challenges focus on issues that suggest the need for obtaining sufficient qualified and trained staff to fulfill the requirements of using interactive teaching programs in preschool settings. Preschool teachers need support and encouragement to try different ways to introduce ICT resources to preschool children. This study furthers our understudying of how we can develop and enhance children's ability to use different ICT resources including interactive teaching programs.

\section{ACKNOWLEDGEMENT}

The research was made possible in part by a contribution from the Deanship of Scientific Research at King Abdulaziz University awarded to the author.

\section{AUTHOR INFORMATION}

Dr Nahla M. Gahwaji has a Ph.D. degree in Early Childhood Education. He is currently Vice Dean of Home Economics 2009 to date, Chair of Childhood Studies dept 2009 -2010, and Chair of Childhood Studies dept 2009 2010, at King Abdulaziz University, Saudi Arabia.

Dr Nahla M. Gahwaji has participated in the following research projects: (1) Cultural Constructions of Quality in Saudi Preschool Education, BERA Annual conference 2008, (2) Between Reality and expectation: Images from Saudi Preschool Centers, EECERA Annual Conference Exploring Vygotsky's ideas: Crossing Borders 2007, and (3) The Status of Preschool Teachers in Saudi Arabia: Controversial and Challenging Concerns, International Conference on the Status of Muslim Women in Contemporary Societies: Realities and Prospects, International Institute for Muslim Unity

\section{REFERENCES}

1. Al-Biblawi, H. (2001). Education in Saudi Arabia (third edition).Jeddah: Tuhama.

2. Char, C. (1990). Interactive technology and the young child. Newton, MA: Center for Learning, Teaching, and Technology Education.

3. Cuban, L. (2001) Oversold and Underused: Computers in the Classroom. Cambridge, MA: Harvard University Press.

4. Cunningham, A. \& Stanovich, K. (1997). Early Reading Acquisition and its Relation to Reading Experience and Ability Ten Years Later. Developmental Psychology, 33: 934-945.

5. Davis, B. \& Shade, D. (1999) Integrating technology into the early childhood classroom: the case of literacy learning. Information Technology in Childhood Education, pp. 221-254.

6. $\quad$ Echols, L., West, R., Stanovich, K., \& Zehr, K. (1996). Using Children's Literacy Activities to Predict Growth in Verbal Cognitive Skills: A Longitudinal Investigation. Journal of Educational Psychology, 88: 296-304.

7. Fisher, R. (2000) Developmentally appropriate practice and a National Literacy Strategy, British Journal of Educational Studies, 48 (1), pp. 58-69.

8. Haugen, K. (1998) Using technology to enhance early learning experiences. Child Care Information Exchange, 9/98, pp. 47-55.

9. Haugland, S. (2000). What role should technology be playing in young children's learning? Part 2. Young Children, 55(1), 12-18. 
10. Haugland, S. \& Wright, L. (1997). Young children and Technology. Needham Heights, MA: Allyn and Bacon.

11. Hitchcock, G. \& Hughes, D. (1995) Research and the Teacher (London, Routledge).

12. Kumtepe, T. (2006) "The effects of computers on Kindergarten's social skills", The Turkish Online Journal of Educational Technology - TOJET, volume 5 (4), Turkey ISSN: 1303-6521

13. Lewin, C. (2000) Exploring the effects of talking books software in UK primary classrooms. Journal of Research in Reading, 23, 2, pp. 149-157.

14. Liang, P-H. \& Johnson, J. (1999) Using computers to enhance early literacy through play. Computers in the Schools, 15, 1, pp. 55-63.

15. Mcinnes, K. (2002) What are the Educational Experiences of 4-Year-Olds? A comparative study of 4-yearolds in nursery and reception settings, Early Years, 22 (2).pp. 119-127

16. Mioduser, D., Tur-Kaspa, H. \& Leitner, I. (2000) The learning value of computer-based instruction of early reading skills. Journal of Computer Assisted Learning, 16, pp. 54-63.

17. National Association for the Education of Young Children (NAEYC) (1996). Technology and Young Children- Ages 3 through 8 (NAEYC Position Statement). Washington, DC: NAEYC.

18. Pascal, C., Bertram, A. D., Ramsden, F., Georgeson, J., Saunders, M. and Mould, C. (1997) Effective Early Learning: case studies for improvement Hodder and Stoughton

19. Pellin, B., \& Edmonds, E. (2001). Bright Beginnings, 1997-2001. Charlotte, NC: Charlotte Mecklenburg Schools.

20. Stephen, C., Brown. S., Cope, P. \& Waterhouse, S. (2001) All-day Provision For 3-and 4-Year Olds: The Experiences of Children, Parents, Providers and Practitioners. Stirling, University of Stirling.

21. Talley, S., Lancy, F., \& Lee, R. (1997). Children, storybooks, and computers. Reading Horizons, 38, 117128.

22. Van Joolingen, W. (2004) "The PISA framework for assessment of ICT literacy” Online at: http://www.ictliteracy.info/rf.pdf/PISA\%20framework.ppt

23. West, J., Denton, K., \& Reaney, L. (2001). Children's Reading and Mathematics Achievement in Kindergarten and First Grade (NCES 2002-125). U.S. Department of Education. National Center for Education Statistics. Washington, DC: U.S. Government Printing Office.

24. Whitehead, M. (1999) Supporting Language and Literacy Development in the Early Years (Buckingham, OUP).

25. Wood, J. (2002). Early Literacy and Learning Model. Jacksonville, FL: Florida Institute of Education and the University of North Florida. 